Olgu sunumu-Case report

http://dx.doi.org/10.7197/1305-0028.2422

\title{
Olgu sunumu: Doğum eylemi sırasında tanı konulan vaza previa
}

\section{Case report: Vaza previa diagnosed during labor}

\author{
Alev Özer*, Serdar Özer, Mine Kanat Pektaş
}

Kadın Hastalıkları ve Doğum Kliniği (Dr. A. Sözer, Dr. S. Özer), Pazarcık Devlet Hastanesi, TR46700 Kahramanmaraş, Kadın Hastalıkları ve Doğum Anabilim Dalı (Yrd. Doç. Dr. M. K. Pektaş), Kocatepe Üniversitesi Tıp Fakültesi, TR-03103, Afyonkarahisar

\section{Özet}

Nadir görülen bir durum olan vaza previa; fetal kan damarlarının, fetusun prezente olan kısmı yanında ve uterus alt segmenti boyunca, umbilikal kordon veya plasenta desteği olmaksızın seyretmesi olarak tanımlanır. Bu yazıda, doğum eylemi sırasında, amnion zarı palpe edilerek tanı konulan bir vaza previa olgusu tanımlanmış; fetal kan damarlarının bütünlüğünü bozarak veya fetal damarları kompresyona uğratarak perinatal morbidite ve mortalite riskini belirgin ölçüde arttıran bu duruma dikkat çekilmesi amaçlanmıştır.

Anahtar sözcükler: Antepartum kanama, plasenta, vaza previa

\begin{abstract}
Vasa previa is an uncommon condition which is defined when the fetal blood vessels traverse the lower uterine segment beneath the presenting part of the fetus with neither the support of the umbilical cord nor the placenta. The present manuscript describes a case of vasa previa which has been diagnosed by the palpation of amniotic membrane during active labor. Therefore, this case report aims to emphasize the clinical significance of vasa previa which increases perinatal morbidity and mortality due to the compression or destruction of fetal blood vessels within the umbilical cord.
\end{abstract}

Keywords: Antepartum hemorrhage, placenta, vasa previa

Geliş tarihi/Received: 21 Eylül 2013; Kabul tarihi/Accepted: 13 Mayıs 2014

\section{*İletişim adresi:}

Dr. Alev Özer, Kadın Hastalıkları ve Doğum Kliniği, Pazarcık Devlet Hastanesi, TR-46700 Kahramanmaraş. E-posta: serdarztb78@ gmail.com

\section{Giriş}

Vaza previa; fetal kan damarlarının, fetusun prezente olan kısmı yanında ve uterus alt segmenti boyunca, umbilikal kordon veya plasenta desteği olmaksızın seyretmesi olarak tanımlanır. Nadir görülen bir durum olan vaza previa, yaklaşık 3000 doğumdan birini etkilemektedir [1,2].

$\mathrm{Bu}$ yazıda, doğum eylemi sırasında, amnion zarı palpe edilerek tanı konulan bir vaza previa olgusu tanımlanmış; perinatal morbidite ve mortalite riskini belirgin ölçüde arttıran bu duruma dikkat çekilmesi amaçlanmıştır. 


\section{Olgu sunumu}

On dokuz yaşındaki primigravid hasta, son adet tarihine göre gebeliğinin 39'uncu haftasındayken bel ve kasık ağrısı nedeniyle çalışma merkezine başvurdu. Öyküsünden, ikili taramasının, üçlü taramasının, fetal anomali taramasının ve $50 \mathrm{~g}$ oral glukoz tolerans testinin normal olduğu ve gebelik takiplerinde herhangi bir sorun belirlenmediği öğrenildi. Özgeçmiş ve soygeçmişinde özellik yoktu.

Ultrasonografide, vertex prezentasyonu gösteren tek bir canlı fetus bulunduğu ve fetal biyometrik ölçümlerin 39 hafta ile uyumlu olduğu saptandı. Bundan başka, uterus posterior duvarına yerleşmiş grade III plasenta mevcuttu ve amniotik sıvı indeksi normaldi. Aşağı yerleşimli plasenta veya plasenta previa izlenmedi. Pelvik muayenede servikal silinmenin \%80'e ulaştı̆̆1, servikal dilatasyonun $2 \mathrm{~cm}$ olduğu ve aktif amnion akışının olmadığı belirlendi. Kardiotokografi incelemesinde on dakika içinde şiddeti 60$80 \mathrm{mmHg}$ ve süresi 40-60 saniye arasında değişen üç düzenli kontraksiyon kaydedildi ve fetal kalp hızı trasesinin reaktif seyrettiği görüldü. Hasta, aktif doğum eylemi tanısıyla doğumhaneye yatırıld.

Kardiotokografide uterus kontraksiyonları yeterli olarak değerlendirilen hastaya indüksiyon uygulanmadı. İki saat süren spontan eylem takibinde hastanın ağrılarının daha da şiddetlendiği ve vajinal kanamasının olduğu gözlemlendi. Bunun üzerine pelvik muayenesi tekrarlanan hastada servikal silinme ve dilatasyon sirasiyla $\% 80$ ve $4 \mathrm{~cm}$ olarak değerlendirildi. Fetal kalp hızı trasesi reaktif seyretmeye devam eden olguda amnion zarı üzerinde pulsasyon veren tübüler yapılar palpe edildi.

Vaza previa tanısıyla acilen sezaryen doğum yaptırılan hasta, 1. ve 5. dakika Apgar skorları sırasıyla 7 ve 9 olarak kaydedilen, 3670 g ağırlığında bir kız bebek dünyaya getirdi. Gross morfolojik inceleme, plasentada umbilikal kordonun velamentöz insersiyonunu gösterdi (Resim 1). Sezaryenle doğum sirasında ve sonrasında herhangi bir komplikasyon gelişmeyen hasta, cerrahi sonrası 2. günde taburcu edildi.

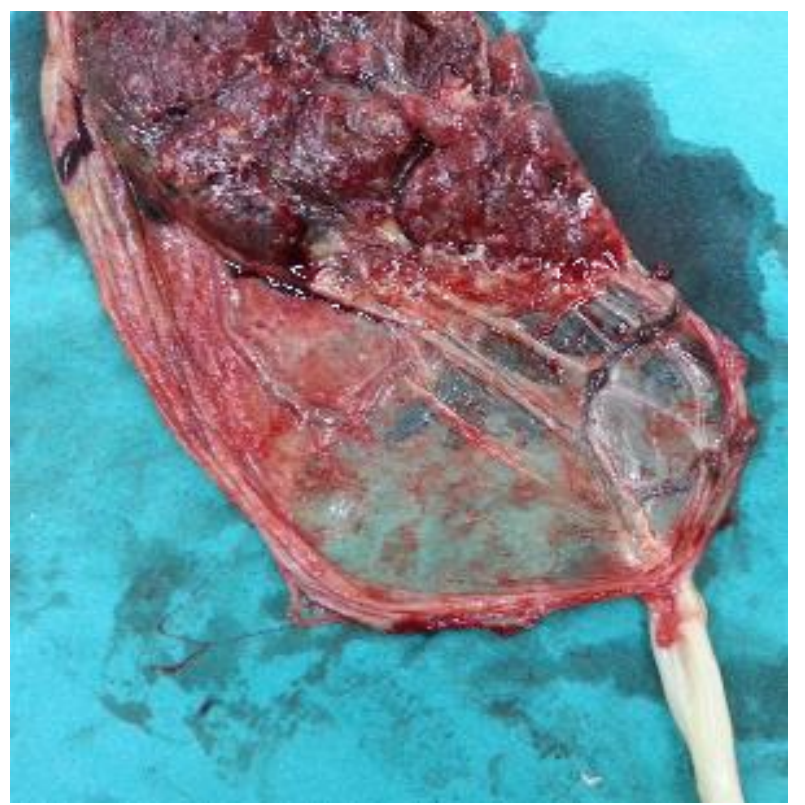

Resim 1. Plasentanın gross morfolojik incelemesi, umbilikal kordonun velamentöz insersiyonunu gösterdi. 


\section{Tartıșma}

Plasenta previa gibi plasentasyon anormallikleri, bilobule plasenta veya suksenturiat lob gibi plasental şekil bozuklukları ve çoğul gebelik, vaza previa için bilinen risk etkenleridir. Yakın tarihli çalışmalar, in vitro fertilizasyon (IVF) sonucu elde edilen gebeliklerde de vaza previa riskinin arttığını göstermiştir. Buna göre, 100 IVF gebeliğinin 14'ünde umbilikal kordonun velamentöz insersiyonu mevcuttur. Genel populasyonda yaklaşık \%4-5 oranında görülen vaza previa, plasenta anormalliği olan hastaların yaklaşık \%33'ünü etkilemektedir [1-3]. Sunulan olguda, belirtilen risk etkenlerinden hiçbiri mevcut değildir. Plasenta yerleşimi ve şekli ile ilgili hiçbir anormallik veya IVF gebeliği söz konusu değildir.

Vaza previa, gebeliğin 2. ve 3. üç ayında ortaya çıkan ağrısız vajinal kanama ile kendini belli eder. Özellikle membran rüptürü, amniotomi veya servikal dilatasyon sırasında fetal kan damarlarının zedelenmesi sonucu vajinal kanama ortaya çıkabilir. Fetal kan damarlarının hasara uğramasıyla fetal dokuların kanlanması azalır. Bazı olgularda ise doğum eylemi sırasında, fetal kan damarları, fetus ile pelvik duvarlar arasında sıkışır. Bu durumda fetal kan damarlarının bütünlüğü bozulmasa da fetal dokulara giden oksijen miktarı düşer. Dolayısıyla, perinatal morbidite ve mortalite riski artar [3, 4]. Sunulan olguda ise, doğum eylemi ilerledikçe belirginleşen vajinal kanama, vaza previa açısından uyarıcı olmuştur.

Gianopoulos ve ark.'ları [6, 7], 1987 yılında, ultrasonografi yardımıyla, doğum öncesi dönemde vaza previa tanısını koyan ilk araştırmacılardır. Daha sonra yayımlanan küçük ölçekli olgu serilerinde ise yüksek çözünürlüklü transvajinal ultrasonografi ve renkli Doppler cihazlarından birlikte yararlanılarak, en erken gebeliğin 16. haftasından itibaren olmak üzere vaza previa tanısı konulabildiği ve böylece perinatal sonuçların iyileştiği gösterilmiştir.

Gebeliğin son altı ayında gerçekleştirilen muayeneler sırasında renkli Doppler ultrasonografi cihazından da yararlanılarak umbilikal kordonun velamentöz insersiyonunun bulunup bulunmadığı kontrol edilebilir. Bundan başka, antepartum vajinal kanaması olan olguların tümü, plasenta previa olgularının hepsi, anormal şekilli plasenta saptanan olgular, çoğul gebelikler ve IVF gebelikleri de vaza previa açısından değerlendirilmelidir. Fetal vücudun pozisyonu nedeniyle bazı vaza previa olguları gözden kaçabilir. Ayrıca, serviksi ön-arka doğrultuda geçen fetal kan damarlarından ziyade serviksi yatay konumda geçen fetal kan damarları görüntülenemeyebilir [6-8]. Sunulan olguda, hiçbir risk etkeninin ve klinik belirtinin olmaması sebebiyle prenatal tanı konulamamış, eylem sırasında vajinal kanama olması nedeniyle plasenta anormalliğinden şüphelenilerek vajinal muayene yapılmıştır. Ancak vajinal muayene sırasında fetal kan damarlarının zedelenebileceği ve bu durumun fetal iyilik haline zarar verebileceği unutulmamalidır.

Gebeliğin 37. haftasından önce tanı konulan vaza previa olgularında, preterm eylemi önlemek amacıyla tokolitik tedavi başlanmalı ve fetal akciğer gelişimini sağlamak için steroid tedavisi uygulanır. $\mathrm{Bu}$ hastalara karın içi basıncını arttıracak hareketleri yapmamaları ve vajinal muayeneden kaçınmaları önerilir. Vaza previa olgularında perinatal sonuçların olumlu olması; doğum öncesi dönemde tanı konulmasına bağlı olduğu kadar membran rüptürü olur olmaz, doğum eylemi başlar başlamaz veya ciddi vajinal kanama görülür görülmez sezaryenle doğum yaptırılmasına da bağlıdır. Prenatal tanı alan vaza previa olgularında doğum sırasındaki ortalama gebelik yaşı, 34,9 2,5 haftadır. Vaza previa ile ilişkili acil komplikasyonların yaratacağ 1 perinatal risk, prenatal tanıya bağlı erken doğum ve hafif prematüriteyle ilişkili perinatal riskin çok üzerindedir. $\mathrm{Bu}$ nedenle, gebeliğin son üç ayına girmiş olgularda, renkli Doppler ultrasonografiden yararlanılarak plasenta yerleşimi ve şekli tanımlanmalı, serviksin yakınında fetal damarların bulunup bulunmadığına bakılmalıdır $[9,10]$. 
Sonuç olarak; plasentasyon anormalliği saptanan tüm olgular, IVF gebelikleri ve çoğul gebelikler vaza previa açısından değerlendirilmeli, eylem sırasında vajinal kanama gözlemlenen düşük riskli olgularda vaza previa olabileceği düşünülmeli ve ayırıcı tanı için pelvik muayene ve ultrasonografi birlikte gerçekleştirilmelidir.

\section{Kaynaklar}

1. Kouach J, Hafidi R, Moussaoui RD, Dehayni M. Vasa previa. J Obstet Gynaecol Can 2010; 32: 203-4.

2. Markham KB, O'Shaughnessy RW. Placental vasa previa. Lancet 2011; 377: 1102.

3. Rosenberg T, Pariente G, Sergienko R, Wiznitzer A, Sheiner E. Critical analysis of risk factors and outcome of placenta previa. Arch Gynecol Obstet 2011; 284: 47-51.

4. Bronsteen R, Whitten A, Balasubramanian M, Lee W, Lorenz R, Redman M. Vasa previa: Clinical presentations, outcomes, and implications for management. Obstet Gynecol 2013; 122: 352-7.

5. Rao KP, Belogolovkin V, Yankowitz J, Spinnato JA 2nd. Abnormal placentation: Evidence-based diagnosis and management of placenta previa, placenta accreata, and vasa previa. Obstet Gynecol Surv 2012; 67: 503-19.

6. Kanda E, Matsuda Y, Kamitomo M, Maeda T, Mihara K, Hatae M. Prenatal diagnosis and management of vasa previa: A 6-year review. J Obstet Gynaecol Res 2011; 37: 1391-6.

7. Hasegawa J, Farina A, Nakamura M, Matsuoka R, Ichizuka K, Sekizawa A, Okai T. Analysis of the ultrasonographic findings predictive of vasa previa. Prenat Diagn 2010; 30: 1121-5.

8. Nishtar A, Wood PL. Is it time to actively look for vasa previa? J Obstet Gynaecol 2012; 32: 413-8.

9. Ioannou C, Wayne C. Diagnosis and management of vasa previa: A questionnaire survey. Ultrasound Obstet Gynecol 2010; 35: 205-9.

10. Robinson BK, Grobman WA. Effectiveness of timing strategies for delivery of individuals with vasa previa. Obstet Gynecol 2011; 117: 542-9. 